\title{
PLANEJAMENTO FINANCEIRO DE FLUXO DE CAIXA COMO FERRAMENTA DE GESTÃO PARA MICROEMPRESAS
}

\section{ARTIGO ORIGINAL}

PINHEIRO, Cristiano de Souza ${ }^{1}$, VALENTE FILHO, Argos do Amaral ${ }^{2}$, DUARTE, Sabrina Kelly de Melo $^{3}$, VIEIRA, Jonathan de Almeida ${ }^{4}$, ROBERTO, José Carlos Alves $^{5}$, SERRA, Meg Rocha da Cunha ${ }^{6}$, LOPES, Nelânia Ferreira ${ }^{7}$

PINHEIRO, Cristiano de Souza. Et al. Planejamento financeiro de fluxo de caixa como ferramenta de gestão para microempresas. Revista Científica Multidisciplinar Núcleo do Conhecimento. Ano. 06, Ed. 11, Vol. 03, pp. 117-137. Novembro 2021. ISSN: 2448-0959, Link de acesso:

https://www.nucleodoconhecimento.com.br/contabilidade/gestao-para-

microempresas, DOI: 10.32749/nucleodoconhecimento.com.br/contabilidade/gestaopara-microempresas

\section{RESUMO}

Esta pesquisa tem como objetivo apresentar o fluxo de caixa como uma ferramenta imprescindível para gestão das microempresas e, assim, evidenciar a necessidade de aperfeiçoamento nos aspectos relevantes que influenciam seus processos operacionais e financeiros. O fluxo de caixa é um instrumento essencial para a administração dos recursos disponíveis e fonte para o controle de capital de giro, o qual também contribui para o sucesso e ascensão da empresa. Desta forma, por se

\footnotetext{
${ }^{1}$ Graduanda do curso de Ciências Contábeis.

${ }^{2}$ Graduando do curso de Ciências Contábeis.

${ }^{3}$ Graduando do curso de Ciências Contábeis.

${ }^{4}$ Graduando do curso de Ciências Contábeis.

${ }^{5}$ Orientador. Mestre em Engenharia de produção. Especialista Logística empresarial. Graduado em Administração com Ênfase em Marketing.

${ }^{6}$ Orientadora. Mestra em Engenharia de Processos Industriais pela UFPA, especialista em Controladoria e Auditoria Contábil pelo Ciesa, Graduada em Ciências Contábeis pelo Centro Universitário do Norte. Graduada em Ciências Econômicas pelo Centro Universitário do Norte.

${ }^{7}$ Especialista em Auditoria Contábil, Financeira e Tributaria e Graduada em Ciências Contábeis.
}

RC: 100720

Disponível em: https://www.nucleodoconhecimento.com.br/contabilidade/gestaopara-microempresas 
tratar de uma pesquisa bibliográfica, realizou-se primeiramente a escolha de um tema e em seguida a seleção de livros e artigos na busca por modelos, controles e planejamentos que visam as movimentações financeiras. Seu objetivo é mostrar que o controle de fluxo de caixa é essencial para manter as microempresas saudáveis financeiramente. Assim, posto que muitas empresas ainda têm dificuldades em se estabilizar no mercado, adotou-se a seguinte pergunta problema: De que forma o controle de fluxo de caixa poderá atender as necessidades para o planejamento financeiro na gestão das microempresas? Em resposta à pesquisa, foi possível observar que a utilização do fluxo de caixa nas empresas pode oferecer melhorias e transparência nos resultados financeiros e na real necessidade de planejamento e controle financeiro, contribuindo assim para o prolongamento de suas atividades comerciais e no crescimento dessas empresas.

Palavras-chave: Fluxo de caixa, Microempresas, Ferramentas de gestão.

\section{INTRODUÇÃO}

Vellardo (2010) ressalta que o artigo objetiva a busca por ferramentas e técnicas que possam se tornar aceitáveis em um mercado cada vez mais exigente, e um plano de gerenciamento de fluxo de caixa se faz fundamental tanto para organizações bem estruturadas como para organizações com dificuldades financeiras.

levantamento de dados dessa pesquisa deu-se por meio de uma pesquisa bibliográfica com base em materiais já elaborados. Desta forma, após a escolha do tema, foram selecionados livros, artigos e conceitos relacionados ao controle operacional e ao planejamento financeiro voltado ao fluxo de caixa que possibilitem o conhecimento técnico científico. O artigo consiste em uma pesquisa explicativa que visa demonstrar os fatos contábeis e descrever e interpretar a apuração dos resultados. Assim, ainda em relação aos procedimentos técnicos, o artigo evidencia os diversos aspectos que devem ser considerados na implantação do planejamento com foco no controle de fluxo de caixa como ferramenta de gestão destinada às microempresas.

RC: 100720

Disponível em: https://www.nucleodoconhecimento.com.br/contabilidade/gestaopara-microempresas 
Conforme Ribeiro (2013), as atividades operacionais podem ser consideradas uma das principais geradoras de recursos de uma empresa, que compreende os recebimentos de suas vendas e empréstimos a funcionários, pagamentos de compra de matéria prima e seus fornecedores, etc. Contudo, não são classificadas como operacionais, as atividades que se enquadram como investimentos e financiamentos.

O Fluxo de caixa é fundamental para uma empresa, no entanto, para que este funcione de forma adequada, tem-se a necessidade de se dispor de mecanismos auxiliares, importantes para tomada de decisão, que promovam ao gestor um controle mensal e até mesmo diário das movimentações monetárias da empresa, a fim de facilitar o gerenciamento de recursos e evitar prejuízos futuros.

Nesse contexto, o presente artigo adotou a seguinte pergunta problema: De que forma o controle de fluxo de caixa poderá atender as necessidades para o planejamento financeiro na gestão das microempresas? E definiu como objetivo principal mostrar aos gestores que o controle de fluxo de caixa é essencial para manter as microempresas saudáveis financeiramente.

Assim, tendo em vista que o mercado tem se tornado cada vez mais exigente e competitivo, o presente estudo se justifica na medida em que busca propor formas de controle e avaliação sobre seus débitos e créditos. Desta forma, destaca-se a importância de atingir tal objetivo, pois o resultado desse estudo irá auxiliar gestores de empresas a compreenderem a importância do planejamento financeiro.

Com foco na melhoria dos resultados e na projeção de sua atuação no mercado, é possível deixar evidente a importância do fluxo de caixa na tomada de decisões dos gestores, por ser um dispositivo administrativo desenvolvido para movimentar o faturamento e as despesas de uma empresa. No entanto, um planejamento de caixa mal elaborado pode vir a prejudicar sua situação financeira e atrapalhar nas decisões futuras. 
Logo, o estudo tem como propósito mostrar, aos gestores das microempresas, ferramentas específicas para o melhor desenvolvimento de suas atividades operacionais, além do fluxo de caixa como um importante instrumento gerencial para administrar as finanças, auxiliando na tomada de decisões que impactarão o futuro de uma empresa.

\section{FUNDAMENTAÇÃO TEÓRICA}

Se trata de desafios enfrentados no dia a dia pelas empresas quando se fala de gerenciamento de seus negócios sempre com o foco no crescimento e longevidade de suas atividades (MARCONDES et al., 2017).

\subsection{PLANEJAMENTO FINANCEIRO}

ludícibus et al. (2009) conceituam que os ativos diferidos são ativos a serem pagos por despesas operacionais (ou custos) que estão em desenvolvimento na empresa. Assim, os gastos de implantação e pré-operacionais, no geral, são um grupo de contas a serem aplicadas em novos investimentos. Aluguel de uma nova sede, organização e construção, por exemplo, são gastos submetidos no início das operações.

Tabela 01: Ciclo Financeiro

\begin{tabular}{|c|c|c|}
\hline $\begin{array}{l}\text { Planejamento } \\
\text { Financeiro }\end{array}$ & Tomadores de decisões & Decisões \\
\hline $\begin{array}{l}\text { - Instituições } \\
\text { Financeiras }\end{array}$ & - Administradores e sócios & $\begin{array}{l}\text { - Diminuição de } \\
\text { custos e despesas }\end{array}$ \\
\hline - Demanda e oferta & - Investidores & $\begin{array}{l}\text { - Aumento na } \\
\text { produtividade }\end{array}$ \\
\hline $\begin{array}{l}\text { - Objetivos a serem } \\
\text { traçados }\end{array}$ & - Gerência e produção & - Equilíbrio nas contas \\
\hline
\end{tabular}

Fonte: Salazar e Benedicto (2010)

RC: 100720

Disponível em: https://www.nucleodoconhecimento.com.br/contabilidade/gestaopara-microempresas 
O Planejamento passa por várias fases e para que se chegue a uma avaliação positiva ou de sucesso, com um plano de ação bem definido a fim de se atingir uma determinada meta, faz-se necessário entender que os mecanismos que o compõem estão sistematicamente ligados (CFC, 2009).

Ter uma visão geral é essencial para entender o real papel da contabilidade como veículo e suporte na escolha das decisões. Ela permite o melhor entendimento do aspecto econômico da empresa e auxilia na gestão dos recursos financeiros da mesma, definindo o que deve ser aplicado em um determinado tempo, lugar, serviço ou despesa, o que se pode investir, como custear, como administrar essa despesa, etc. (SALAZAR e BENEDICTO, 2010).

\subsection{DEFINIÇÃO DE MICROEMPRESA}

Segundo Machado (2020), as microempresas se caracterizam pelo porte e pela capacidade de rendimento, ou seja, pela soma de seus ganhos ocorridos em um período. Desta forma, a microempresa pode ser: sociedade empresarial, individual e simples de competência limitada adequadamente lavrada, e se define pela receita bruta anual de até $360.000,00$.

- Microempresas: Receita bruta anual igual ou inferior a $R \$ 360.000,00$;

- Empresa de Pequeno Porte: Receita bruta anual superior a $\mathrm{R} \$ 000,00$ e igual ou inferior a $\mathrm{R} \$ 4.800,000,00$ (SEBRAE).

Nesse contexto, a Lei Complementar N. 123, de 14 de dezembro de 2006, estabelece que:

Art. 1으 Esta Lei Complementar estabelece normas gerais relativas ao tratamento diferenciado e favorecido a ser dispensado às microempresas e empresas de pequeno porte no âmbito dos Poderes da União, dos Estados, do Distrito Federal e dos Municípios.

$\S 10$ Cabe ao Comitê Gestor de que trata o inciso I do caput do art. 2ํ desta Lei Complementar apreciar a necessidade de revisão dos valores expressos em moeda nesta Lei Complementar.

RC: 100720

Disponível em: https://www.nucleodoconhecimento.com.br/contabilidade/gestaopara-microempresas 
Art. 3ㅇ Para os efeitos desta Lei Complementar, consideram-se microempresas ou empresas de pequeno porte a sociedade empresária, a sociedade simples e o empresário a que se refere o art. 966 da Lei $n^{\circ} 10.406$, de 10 de janeiro de 2002, devidamente registrados no Registro de Empresas Mercantis ou no Registro Civil de Pessoas Jurídicas, conforme o caso, desde que:

I - no caso das microempresas, o empresário, a pessoa jurídica, ou a ela equiparada, aufira, em cada ano-calendário, receita bruta igual ou inferior a $\mathrm{R} \$ 240.000,00$ (duzentos e quarenta mil reais);

$\S 1$ - Considera-se receita bruta, para fins do disposto no caput deste artigo, o produto da venda de bens e serviços nas operações de conta própria, o preço dos serviços prestados e o resultado nas operações em conta alheia, não incluídas as vendas canceladas e os descontos incondicionais concedidos.

$\S 2$ № caso de início de atividade no próprio ano-calendário, o limite a que se refere o caput deste artigo será proporcional ao número de meses em que a microempresa ou a empresa de pequeno porte houver exercido atividade, inclusive as frações de meses.

$\S$ 14. Para fins de enquadramento como microempresa ou empresa de pequeno porte, poderão ser auferidas receitas no mercado interno até o limite previsto no inciso II do caput ou no $\S 2^{\circ}$, conforme o caso, e, adicionalmente, receitas decorrentes da exportação de mercadorias ou serviços, inclusive quando realizada por meio de comercial exportadora ou da sociedade de propósito específico prevista no art. 56 desta Lei Complementar, desde que as receitas de exportação também não excedam os referidos limites de receita bruta anual (BRASIL, 2006).

\subsection{CONTROLE FINANCEIRO PARA A GESTÃO DAS MICROEMPRESAS}

Esse controle é indispensável para a administração de uma microempresa e ocorre através de registros de informações que apresentam com exatidão o saldo do estoque das mercadorias armazenadas, dos registros de entrada e saída de caixa e dos movimentos bancários.

O diretor financeiro tem por finalidade acompanhar as atividades ocorridas diariamente. Esse controle entre a verificação e a realização deve ocorrer para que o caixa não se torne extenuante, portanto, se recomenda que esse planejamento seja realizado dia após dia (VELLARDO,2010).

RC: 100720

Disponível em: https://www.nucleodoconhecimento.com.br/contabilidade/gestaopara-microempresas 
O sistema de controle deve ser escolhido de acordo com as particularidades de cada organização, no entanto, este deve levar em consideração os objetivos da microempresa de forma a propiciar aos gestores mensurar e avaliar os resultados. $\mathrm{O}$ controle pode ser considerado como um sistema de feedback, o qual auxilia a tomada de decisão na busca da eficiência organizacional (ATKINSON et al., 2008, p. 581)

Conforme Sá (2008, p. 11), o fluxo de caixa permite a análise de tendências, servindo de base para o planejamento do fluxo de caixa projetado. Além de permitir a verificação dos motivos dos desvios (se há falhas no planejamento projetado ou de administração), o fluxo de caixa projetado permite a visualização de como se comportarão as entradas e as saídas de recursos em um período futuro, identificando se haverá falta ou excesso de recursos, o que possibilita verificar se a empresa precisará utilizar capitais de terceiros ou se a mesma será capaz de custear suas operações.

\subsection{PRINCIPAIS FERRAMENTAS PARA A GESTÃO FINANCEIRA}

Tendo em vista que um dos maiores desafios do microempreendedor individual e da microempresa é realizar um planejamento financeiro adequado, o auxílio dos profissionais da contabilidade é de extrema importância para a realização do controle dos dados contábeis do empreendimento, a fim de gerar o fluxo de caixa e o balanço comercial da empresa (MORAIS, 2010).

Dentre as ferramentas para análise e planejamento financeiro, Morais (2010, p. 80) menciona: o fluxo de caixa (ferramenta na qual relata os recebimentos e os pagamentos a serem realizados pela empresa); o demonstrativo de resultado (que avalia o volume de vendas, o custo de mercadorias vendidas e as despesas que são fixas e variáveis); e o balanço patrimonial (que calcula o valor do patrimônio líquido da empresa e demonstra as obrigações e as contas a receber).

RC: 100720

Disponível em: https://www.nucleodoconhecimento.com.br/contabilidade/gestaopara-microempresas 


\subsubsection{FLUXO DE CAIXA PARA MICROEMPRESAS}

Engloba todas as movimentações realizadas na produção e saída de bens e serviços que possam ser classificadas como atividades de financiamento e investimento, e geralmente aparecem nas demonstrações do Resultado (IUDíCIBUS et al., 2009).

O Fluxo de caixa é uma ferramenta de organização e avaliação financeira que, quando bem desenvolvida, ajuda no gerenciamento dos recursos. É um dispositivo crucial na segurança e na agilidade de informações relacionadas às operações de uma empresa. Por isso, o administrador financeiro deve sempre se manter atualizado na economia mundial e ter conhecimentos das técnicas gerenciais para elaborar projeções de estoque e custos que não se tornem despesas desnecessárias para o caixa.

Sousa (2007) comenta que o uso da expressão fluxo de caixa se refere a toda movimentação de recursos da microempresa referente ao dinheiro em espécie ou representado como tal. Nesse contexto, o autor ainda acrescenta que, com a globalização, deve-se ter uma amplitude maior quanto à expressão fluxo de caixa, pois muitas operações são realizadas via internet, transferência bancária, cheques ou depósitos diretamente nos bancos, o que possibilita dizer que o fluxo de caixa vai além, envolvendo todos os pagamentos e recebimentos em geral. Logo, a tabela a seguir mostra o modelo de fluxo de caixa de atividades operacionais indicado para as microempresas em geral.

Tabela 02: Fluxo de Caixa de atividades operacionais - diário - semanal para microempresas

FLUXO DE Período de 01/11/21 á 08/11/21

\begin{tabular}{l|l|l|l|l|l|l|l|l} 
CAIXA & 01 & 02 & 03 & 04 & 05 & 06 & 07 & 08 \\
\cline { 2 - 4 } & Nov & Nov & Nov & Nov & Nov & Nov & Nov & Nov \\
\hline Atividades & & & & & & & &
\end{tabular}

RC: 100720

Disponível em: https://www.nucleodoconhecimento.com.br/contabilidade/gestaopara-microempresas 


\begin{tabular}{|c|c|c|c|c|c|c|c|c|}
\hline $\begin{array}{l}\text { Saldo do } \\
\text { Caixa }\end{array}$ & 0,00 & 1.585 & 1.085 & 1.135 & $\begin{array}{l}13.48 \\
5\end{array}$ & $\begin{array}{l}19.48 \\
5\end{array}$ & $\begin{array}{l}37.48 \\
5\end{array}$ & $\begin{array}{l}35.56 \\
5\end{array}$ \\
\hline $\begin{array}{ll}\text { Vendas } & \text { c/ } \\
\text { Cartão } & \text { de } \\
\text { Crédito } & \end{array}$ & 0,00 & 1.500 & $\begin{array}{l}800,0 \\
0\end{array}$ & 2.500 & 3.000 & 5.000 & $\begin{array}{l}500,0 \\
0\end{array}$ & \\
\hline $\begin{array}{l}\text { Recebimento } \\
\text { s }\end{array}$ & 60,00 & 1.000 & 2.000 & 3.000 & 4.000 & 4.000 & 80,00 & \\
\hline Boletos & 80,00 & 800,00 & 2.000 & 5.000 & 3.000 & 3.000 & 0,00 & \\
\hline Vendas & 35,00 & 700,00 & 1.500 & 4.500 & 3.000 & 3.500 & $\begin{array}{l}500,0 \\
0\end{array}$ & \\
\hline $\begin{array}{l}\text { Aumento de } \\
\text { Capital }\end{array}$ & $\begin{array}{l}10.00 \\
0\end{array}$ & 0,00 & 0,00 & 0,00 & 0,00 & 0,00 & 0,00 & \\
\hline $\begin{array}{l}\text { Resgate de } \\
\text { Aplicação }\end{array}$ & 0,00 & 0,00 & 0,00 & $\begin{array}{l}500,0 \\
0\end{array}$ & 0,00 & 0,00 & 0,00 & \\
\hline $\begin{array}{l}\text { Outras } \\
\text { Recebimento } \\
\text { s }\end{array}$ & 40,00 & 0,00 & 0,00 & 0,00 & 0,00 & 0,00 & 0,00 & \\
\hline $\begin{array}{ll}\text { Total de } & \text { de } \\
\text { entradas } & \end{array}$ & $\begin{array}{l}10.21 \\
5\end{array}$ & 4.000 & 6.300 & $\begin{array}{l}15.50 \\
0\end{array}$ & $\begin{array}{l}13.00 \\
0\end{array}$ & $\begin{array}{l}21.50 \\
0\end{array}$ & 1.080 & \\
\hline Pagamentos & & & & & & & & \\
\hline Salários & 0,00 & 0,00 & 0,00 & 0,00 & 7.000 & 0,00 & 0,00 & \\
\hline Aluguel & 2,500 & 0,00 & 0,00 & 0,00 & 0,00 & 0,00 & 0,00 & \\
\hline $\begin{array}{l}\text { Matéria- } \\
\text { prima }\end{array}$ & 1.500 & 0,00 & 0,00 & 3.000 & 0,00 & 0,00 & 0,00 & \\
\hline $\begin{array}{l}\text { Fornecedor } \\
\text { A }\end{array}$ & 0,00 & 2.000 & 0,00 & 0,00 & 0,00 & 0,00 & 0,00 & \\
\hline $\begin{array}{l}\text { Fornecedor } \\
\text { B }\end{array}$ & 0,00 & 0,00 & 0,00 & 0,00 & 0,00 & 1.500 & 0,00 & \\
\hline telefone & 0,00 & 0,00 & $\begin{array}{l}500.0 \\
0\end{array}$ & 0,00 & 0,00 & 0,00 & 0,00 & \\
\hline
\end{tabular}

RC: 100720

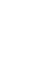




\begin{tabular}{|c|c|c|c|c|c|c|c|}
\hline Empréstimos & 4.000 & 0,00 & 0,00 & 0,00 & 0,00 & 0,00 & 3.000 \\
\hline $\begin{array}{l}\text { Vale } \\
\text { transporte }\end{array}$ & $\begin{array}{l}630.0 \\
0\end{array}$ & 0,00 & 0,00 & 0,00 & 0,00 & 0,00 & 0,00 \\
\hline Contador & 0,00 & 0,00 & 2.500 & 0,00 & 0,00 & 0,00 & 0,00 \\
\hline Juros & 0,00 & 250,00 & 0,00 & $\begin{array}{l}150,0 \\
0\end{array}$ & 0,00 & 0,00 & 0,00 \\
\hline Saldo Final & 8.630 & 4.500 & 6.250 & 3.150 & 7.000 & 3.500 & 3.000 \\
\hline $\begin{array}{l}\text { Outros (pg) } \\
\text { saldo do dia }\end{array}$ & 1.585 & $\begin{array}{l}(500,00 \\
)\end{array}$ & 50,00 & $\begin{array}{l}12.35 \\
0\end{array}$ & 6.000 & $\begin{array}{l}18.00 \\
0\end{array}$ & $\begin{array}{l}(1.920 \\
)\end{array}$ \\
\hline
\end{tabular}

Fonte: Vellardo. 2010

Para que a microempresa possa utilizar essas informações com mais transparência, a fim de analisar com maior facilidade esses dados, sugere-se o uso de planilhas elaboradas em excel ou programas especializados.

$\mathrm{Na}$ tabela acima é possível explicar essa elaboração de fluxo de caixa de forma analítica, onde identificou-se, primeiramente, o período trabalhado, neste caso uma semana (7 dias). Mesmo que o saldo inicial esteja zerado no início do mês, este deve ser lançado no fluxo de caixa e, as entradas menos os pagamentos, serão lançados no saldo do dia seguinte. Essas informações configuram o quanto estará disponível em caixa.

Groppelli (2009) defende que a capacidade do capital de giro depende de recursos internos ou externos. Sendo assim, a microempresa que tem fluxo de caixa possui um potencial diferenciado para programar decisões de investimento, pagamentos e financiamentos.

O fluxo da caixa mais indicado para as microempresas é o de atividades operacionais. Os fluxos de caixa que advém das atividades operacionais são derivados das principais atividades que geram receita para a empresa, sendo assim,

RC: 100720

Disponível em: https://www.nucleodoconhecimento.com.br/contabilidade/gestaopara-microempresas 
geralmente são resultados de transações e de outros eventos que estão presentes quando se calcula o lucro líquido ou prejuízo da empresa. (CPC, 2010).

\subsubsection{CONTAS A PAGAR}

Mendonça (2010) explica que o conceito de contas a pagar diz respeito às obrigações de uma empresa a serem pagas em um determinado período. Ao usar essa ferramenta a empresa não corre o risco de deixar de pagar suas contas nas datas de seus vencimentos por simples esquecimento. Tem objetivo de evitar que as empresas paguem multas por atraso ou que estas se tornem uma empresa inadimplente. A organização dessas contas mostrará ao empresário a real necessidade de capital para fazer essas liquidações.

Salazar e Benedicto (2010) apontam que os registros devem ser lançados segundo sua natureza, apreciando os procedimentos contábeis, que serão lançados em um grupo de contas específicas, conhecido como CONTAS A PAGAR. Cada empresa cria seu plano de contas conforme sua atividade para registrar suas transações contábeis de forma elucida.

Tabela 03: Balanço Patrimonial - Passivo - Contas a Pagar

BALANÇO PATRIMONIAL

\begin{tabular}{|c|c|c|c|c|}
\hline \multirow{3}{*}{$\begin{array}{l}\text { ATIVO } \\
\text { CIRCULANTE }\end{array}$} & \multicolumn{4}{|c|}{ PASSIVO } \\
\hline & \multicolumn{4}{|c|}{ CIRCULANTE } \\
\hline & \multicolumn{3}{|c|}{ Duplicatas a Pagar } & $15.000,00$ \\
\hline Disponível & \multicolumn{3}{|c|}{ Salários a Pagar } & $7.000,00$ \\
\hline \multirow[t]{3}{*}{ Total do disponível } & $\begin{array}{l}\text { Encargos } \\
\text { Recolher }\end{array}$ & Sociais & & $1.200,00$ \\
\hline & $\begin{array}{l}\text { Impostos } \\
\text { Recolher }\end{array}$ & Federais & & $2.500,00$ \\
\hline & $\begin{array}{l}\text { Impostos } \\
\text { Recolher }\end{array}$ & Estaduais & & $2.000,00$ \\
\hline
\end{tabular}

RC: 100720

Disponível em: https://www.nucleodoconhecimento.com.br/contabilidade/gestaopara-microempresas 
Total do disponível

Impostos Municipais a $1.500,00$

Recolher

Créditos

Empréstimos Bancários

$12.000,00$

Total do Realizável a Curto

Provisão para IRPJ

$10.000,00$

Prazo

Despesas Antecipadas

Provisão para Cont. Social $8.000,00$

Total das Despesas

Dividendos a Pagar

$4.000,00$

Antecipadas

\begin{tabular}{|c|c|c|}
\hline & $\begin{array}{ll}\text { Aluguéis } & \text { Recebidos } \\
\text { Antecipados } & \end{array}$ & 0,00 \\
\hline TOTAL DO CIRCULANTE & TOTAL DO CIRCULANTE & $63.200,00$ \\
\hline ATIVO NÃO CIRCULANTE & $\begin{array}{l}\text { PASSIVO NÃC } \\
\text { CIRCULANTE }\end{array}$ & \\
\hline $\begin{array}{l}\text { Realizável a Longo Prazo - } \\
\text { Atividades }\end{array}$ & Exigível a Longo Prazo & \\
\hline Usuais & Financiamento & $10.000,00$ \\
\hline $\begin{array}{l}\text { Total do Realizável a Longo } \\
\text { Prazo }\end{array}$ & Empréstimos bancários & $15.800,00$ \\
\hline Investimentos & $\begin{array}{l}\text { Empréstimos } \quad d e \\
\text { coligadas/control }\end{array}$ & 0,00 \\
\hline \multirow[t]{2}{*}{ Total dos Investimentos } & Empréstimos de sócios & 0,00 \\
\hline & $\begin{array}{l}\text { Total do Exigível a Longo } \\
\text { Prazo }\end{array}$ & $25.800,00$ \\
\hline $\begin{array}{l}\text { Imobilizados - Bens em } \\
\text { Operação }\end{array}$ & $\begin{array}{l}\text { Resultados não } \\
\text { Realizados }\end{array}$ & \\
\hline Total do Imobilizado & $\begin{array}{l}\text { Lucros em Participações } \\
\text { Societárias }\end{array}$ & 0,00 \\
\hline
\end{tabular}

RC: 100720

Disponível em: https://www.nucleodoconhecimento.com.br/contabilidade/gestaopara-microempresas 


\begin{tabular}{|c|c|c|}
\hline & $\begin{array}{l}\text { Ganhos de } \\
\text { Doações/Subvenções } \\
\text { p/ Investimento }\end{array}$ & 0,00 \\
\hline & ( - ) Encargos Tributários & 0,00 \\
\hline Intangível & $\begin{array}{l}\text { Total do Res. Não } \\
\text { Realizados }\end{array}$ & 0,00 \\
\hline \multirow[t]{6}{*}{ Total do Intangível } & $\begin{array}{l}\text { TOTAL DO NÃO } \\
\text { CIRCULANTE }\end{array}$ & \\
\hline & PATRIMÔNIO LÍQUIDO & \\
\hline & Capital Social & $25.000,00$ \\
\hline & ( - ) Capital a Realizar & \\
\hline & Reservas de Capital & $8.000,00$ \\
\hline & $\begin{array}{l}\text { Ajuste de Avaliação } \\
\text { Patrimonial }\end{array}$ & $2.000,00$ \\
\hline \multirow[t]{4}{*}{$\begin{array}{l}\text { TOTAL DO NÃO } \\
\text { CIRCULANTE }\end{array}$} & Reservas de Lucros & $5.000,00$ \\
\hline & ( - ) Ações em Tesouraria & \\
\hline & ( - ) Prejuízos Acumulados & \\
\hline & $\begin{array}{l}\text { TOTAL DO PATRIMÔNIO } \\
\text { LÍQUIDO }\end{array}$ & \\
\hline TOTAL DO ATIVO & TOTAL DO PASSIVO & $129.000,00$ \\
\hline
\end{tabular}

Fonte: ludícibus et al. 2009

\subsubsection{CONTAS A RECEBER}

Representam todos os direitos a receber tanto de serviços prestados como de vendas de produtos. Essas operações não descrevem a principal finalidade da

RC: 100720

Disponível em: https://www.nucleodoconhecimento.com.br/contabilidade/gestaopara-microempresas 
organização, mas são inerentes às suas atividades (IUDÍCIBUS et al., 2009). É necessário saber separar detalhadamente as contas de seu propósito especifico (CLIENTES) e classificá-las em OUTROS CRÉDITOS, para lançá-las no decorrer do próximo exercício, subsequentemente a data do balanço que se encontra no ATIVO CIRCULANTE. Porém, os produtos ou serviços podem ser vendidos a longo prazo, por meio de prestação com parcelamento, esta ação no momento do fechamento do exercício se configura como REALIZÁVEL A LONGO PRAZO. Conforme sugere a figura abaixo:

Tabela 04: Balanço Patrimonial - Ativo - Contas a Receber

BALANÇO PATRIMONIAL

\begin{tabular}{|c|c|c|}
\hline ATIVO & & PASSIVO \\
\hline CIRCULANTE & & CIRCULANTE \\
\hline Disponível & & \\
\hline Caixa & $10.000,00$ & \\
\hline Banco Conta Movimento & $28.000,00$ & \\
\hline $\begin{array}{l}\text { Aplicação de Liquidez } \\
\text { imediata }\end{array}$ & $3.500,00$ & \\
\hline Total do disponível & $41.500,00$ & \\
\hline Créditos & & \\
\hline Duplicatas a Receber & $15.000,00$ & \\
\hline Empréstimos a Receber & $2.500,00$ & \\
\hline Estoque de Mercadorias & $20.000,00$ & \\
\hline $\begin{array}{l}\text { Total do Realizável a Curto } \\
\text { Prazo }\end{array}$ & $37.500,00$ & \\
\hline Despesas Antecipadas & & \\
\hline $\begin{array}{l}\text { Total das Despesas } \\
\text { Antecipadas }\end{array}$ & 0,00 & \\
\hline TOTAL DO CIRCULANTE & $79.000,00$ & TOTAL DO CIRCULANTE \\
\hline
\end{tabular}

RC: 100720

Disponível em: https://www.nucleodoconhecimento.com.br/contabilidade/gestaopara-microempresas 


\begin{tabular}{|c|c|c|}
\hline ATIVO NÃO CIRCULANTE & & $\begin{array}{l}\text { PASSIVO NÃO } \\
\text { CIRCULANTE }\end{array}$ \\
\hline $\begin{array}{l}\text { Realizável a Longo Prazo - } \\
\text { Atividades Usuais }\end{array}$ & & Exigível a Longo Prazo \\
\hline $\begin{array}{l}\text { Total do Realizável a Longo } \\
\text { Prazo }\end{array}$ & 0,00 & $\begin{array}{l}\text { Total do Exigível a Longo } \\
\text { Prazo }\end{array}$ \\
\hline Investimentos & & TOTAL NÃO CIRCULANTE \\
\hline Imóveis para Renda & $30.000,00$ & Resultado não Realizados \\
\hline Total dos Investimentos & $30.000,00$ & \\
\hline $\begin{array}{l}\text { Imobilizados - Bens em } \\
\text { Operação }\end{array}$ & & $\begin{array}{l}\text { Total do Res. Não } \\
\text { Realizados }\end{array}$ \\
\hline Veículos & $18.000,00$ & \\
\hline $\begin{array}{l}\text { Móveis, Máquinas e } \\
\text { Equipamentos }\end{array}$ & $30.000,00$ & \\
\hline $\begin{array}{l}\text { Equipamentos de } \\
\text { informática }\end{array}$ & $8.000,00$ & PATRIMÔNIO LÍQUIDO \\
\hline 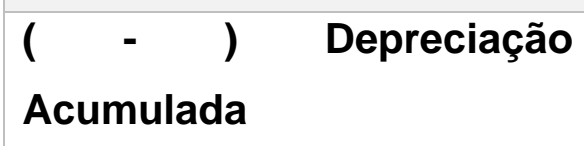 & $-1.000,00$ & $\begin{array}{l}\text { TOTAL DO PATRIMÔNIO } \\
\text { LÍQUIDO }\end{array}$ \\
\hline Total do Imobilizado & $28.000,00$ & \\
\hline Intangível & & \\
\hline $\begin{array}{l}\left(\begin{array}{c}\text { ( } \\
\text { Acumulada }\end{array}\right. \\
\text { Amortização }\end{array}$ & 0,00 & \\
\hline Total do Intangível & 0,00 & \\
\hline $\begin{array}{l}\text { TOTAL DO NÃO } \\
\text { CIRCULANTE }\end{array}$ & $20,000,00$ & \\
\hline TOTAL DO ATIVO & $129.000,00$ & TOTAL DO PASSIVO \\
\hline
\end{tabular}

Fonte: Iudícibus et al., 2009 


\subsubsection{INADIMPLÊNCIA}

Moraes e Gomes (2015) apontam que a inadimplência consiste em uma quebra de contrato. As empresas investem em rendimentos para se estabilizarem no mercado e se esquecem da próxima etapa, que é o recebimento e, quando não o recebem, há impacto no fluxo de caixa.

Vieira (2010) diz que, sendo o risco de não pagamento uma eventualidade esperada, é importante compreender as possíveis causas deste fenômeno a fim de adotar medidas para se antecipar à ocorrência deste problema em novas concessões de crédito.

Sendo assim, algumas das possíveis causas de Inadimplência são:

- Comprar mais do que pode pagar;

- Desemprego;

- Emprestar crédito;

- Incapacidade financeira;

- Falta de planejamento financeiro.

\subsection{CONTROLE E NECESSIDADE DE CAPITAL DE GIRO ATRAVÉS DO FLUXO DE CAIXA}

Ferreira et al. (2011) explicam que o capital de giro de uma microempresa é simbolizado nas atuações do ativo circulante e são representados pelos ativos disponíveis que abrangem as contas a receber e o estoque. De forma mais ampla, esse capital é a demanda da empresa para custear suas atividades sazonais, desde a compra de matéria-prima para a produção dos produtos até a remuneração por sua venda.

Padoveze (2010) aponta que os dados, quando não repassados, impactam os lançamentos estatísticos. Assim, fazendo um levantamento junto aos clientes e revendedores obtém-se uma estimativa que auxilia o gerenciamento. Esse capital é

RC: 100720

Disponível em: https://www.nucleodoconhecimento.com.br/contabilidade/gestaopara-microempresas 
importante para operações financeiras de pequenas empresas, pois é ele quem irá dar subsídios aos compromissos institucionais da mesma. Por essa razão, é necessário manter esse capital para a conservação da entidade, a fim de direcionálos, caso necessário, aos imprevistos que podem acontecer.

De acordo com Braga (2008, p. 81-84), a administração do capital de giro está relacionada aos recursos aplicados no ativo circulante, compostos basicamente pelas disponibilidades, contas a receber e estoques. Assim, a gestão de ativos e passivos circulantes caracteriza a administração do capital de giro. Investimento alto demais em Ativo Circulante reduz a lucratividade da microempresa e investimento baixo demais aumenta o risco de a empresa não honrar com seus compromissos. Assim, as organizações devem buscar um equilíbrio entre a lucratividade e o risco, uma vez que ambas as situações levam à redução do valor da empresa.

\subsection{CICLO OPERACIONAL}

Conforme Salazar e Benedicto (2010), existem duas formas de cálculos com efeitos no caixa em operações: o método direto e o método indireto, que influenciam na DRE. No caso da Demonstração de Fluxo de Caixa, quando o cálculo é igual ao recolhimento menos as despesas operacionais, chamamos de Método direto. Já o Método Indireto, é direcionado a partir dos valores demonstrados, como Lucro Líquido da DRE.

Tabela 05: Ciclo Operacional - Método Direto - Método Indireto

\begin{tabular}{|l|l|l|l|l|}
\hline MÉTODO DIRETO & \multicolumn{3}{l|}{ MÉTODO INDIRETO } \\
\hline Cobrança de clientes & & $\mathbf{2 0 0 . 0 0 0 , 0 0}$ & Lucro Líquido & $\mathbf{9 0 . 0 0 0 , 0 0}$ \\
\hline $\begin{array}{l}\text { Pagamento de salários } \\
\text { Pagamento }\end{array}$ & $\mathbf{1 0 . 0 0 0 , 0 0}$ & & + Depreciação & $\mathbf{1 0 . 0 0 0 , 0 0}$ \\
\hline $\mathbf{a}$ & $\underline{\mathbf{1 7 0 . 0 0 0 , 0 0}}$ & & & \\
\hline Fornecedores & & & & \\
\hline
\end{tabular}

RC: 100720

Disponível em: https://www.nucleodoconhecimento.com.br/contabilidade/gestaopara-microempresas 


\begin{tabular}{l|l|l|l|}
\hline $\begin{array}{l}\text { Caixa Líquido } \\
\text { gerado pelas } \\
\text { atividades }\end{array}$ & $\underline{180.000,00}$ & $\underline{20.000,00}$ & \\
\hline operacionais & & \\
\hline
\end{tabular}

Fonte: Salazar e Benedicto. 2010

\subsubsection{PREVISÃO DE VENDAS}

Quanto ao reconhecimento das receitas de venda, de acordo com o princípio contábil no regime de competência, os produtos e serviços, depois de entregues aos clientes devem ser reconhecidos (receita realizada). Depois de reconhecida deve-se contabilizá-la, ou seja, a mensuração entre 0 ativo entregue ao cliente e a receita equivalente no valor da correção da moeda.

\subsubsection{CONTROLE DE CUSTOS E DESPESAS}

De acordo com ludícibus et al. (2009), os custos dos itens vendidos ou serviços prestados devem ser lançados no exercício correspondente à receita das vendas, produtos e serviços estimados no mesmo período.

Já nas despesas operacionais, se originam das despesas ordenadas ou movimentadas para venda de produtos e administração da empresa, a Lei 6.404/76 determina no item III - as despesas com as vendas, as despesas financeiras, deduzidas das receitas, as despesas gerais e administrativas, e outras despesas operacionais.

Salazar e Benedicto (2010), explicam que com o tempo algumas contas precisam ser dado baixa temos o exemplo dos aluguéis pagos antecipados que encontram-se como um Ativo durante a validade do contrato que depois precisa ser dado baixa na contabilidade. 


\subsection{PLANEJAMENTO DE LUCRO}

ludícibus et al. (2009) trata da importância que dá demonstração do lucro do período, suas destinações e movimentações que foram lançadas no saldo da conta Lucro ou Prejuízos Acumulados, essa demonstração é obrigatória para Limitadas e outros tipos de sociedade.

O art. 186 da Lei das Sociedades por Ações determina:

A demonstração de lucro e prejuízos acumulados isentará:

I - correções monetárias no saldo inicial e ajustes de exercícios anteriores; II - as devoluções de reservas e o lucro líquido;

lii - Transferências para reservas e dividendos também como parte do lucro ao saldo do capital do período.

\subsubsection{DEMONSTRAÇÕES DO RESULTADO PLANEJADA}

ludícibus et al. (2009), a Demonstração do Resultado do Exercício deve-se ser apresentada de forma analítica, com todas as informações das receitas, despesas, ganhos e perdas no período determinando de modo preciso o lucro e prejuízo do exercício, sem se confundir com as contas de divisão ou destinação de verbas que é a conta Lucros Acumulados.

, projeção de vendas é uma forma de avaliar o total de faturamento que uma empresa estima ganhar em um determinado período sendo por ano, mês ou semestre, essa apuração é executada em cima de várias referências como, sazonalidade, capacidade de produção, a economia e comportamento do mercado e essa projeção passa por algumas etapas (BLOG, 2019):

- Deduções: são as despesas variáveis são encargos sobre, frete, venda,

RC: 100720

Disponível em: https://www.nucleodoconhecimento.com.br/contabilidade/gestaopara-microempresas 
- Gastos: esse cálculo também é muito importante no que se refere ao impacto da projeção de vendas pois influencia nas despesas com matéria

- prima e mão de obra, vai variar do volume de vendas para se fazer o volume de compras.

- Investimentos: sempre são necessários para o crescimento da empresa e a projeção atingir seu nível máximo no próximo bimestre ou trimestre um planejamento de investimentos é essencial para a garantia de crescimento do negócio.

- Métodos de lançamentos de vendas:

- 1 - lançamento de vendas em resultados realizados: se baseia em vendas;

- 2 - lançamento de vendas baseada no mercado: fazer pesquisa no mercado de concorrentes;

- 3 - lançamento de vendas pelo ponto de equilíbrio: a venda do produto precisa ser feita.

\section{MATERIAIS E MÉTODOS}

Fonseca (2012) descreve materiais e métodos como sendo um conjunto de estratégias preestabelecidas empregadas pelo pesquisador para se atingir uma determinada meta.

\subsection{PROCEDIMENTOS METODOLÓGICOS.}

A busca pelo conhecimento utiliza métodos de análise que passam por várias etapas, utilizando-se de normas, meios e formas, conhecido como método científico. Portanto, esse estudo possui uma reflexão sobre o tema (ENCINAS e SANTANA, 2019).

RC: 100720

Disponível em: https://www.nucleodoconhecimento.com.br/contabilidade/gestaopara-microempresas 


\subsubsection{QUANTO À NATUREZA}

Zambello (2018) explica que o método indutivo é desenvolvido a partir da análise de estudos já elaborados, com o objetivo de buscar explicações detalhadas sobre um objeto ou fenômeno pouco estudado.

De acordo com Encinas e Santana (2019), promover conhecimento é basicamente contribuir com uma nova visão sobre um fenômeno qualquer. $O$ conhecimento nasce no acúmulo de informações do cotidiano, em leituras, artigos e livros.

Essa pesquisa, portanto, é explicativa e tem como objetivo gerar informações no intuito de agregar conhecimento para a administração gerencial.

\subsubsection{QUANTO AOS FINS}

Conforme Severino (2013), a pesquisa explicativa, além de relatar, busca explorar os fenômenos.

A observação é uma etapa a ser cumprida, pois dará respostas às metas que já haviam sido traçadas, isso tudo acompanhado de um rigoroso planejamento para alcance do sucesso almejado (ZAMBELLO et al., 2018).

Com relação aos fins, essa pesquisa será descritiva, por tratar de assuntos já estudados, porém, com o objetivo de elucidar os dados coletados para um melhor entendimento de sua contextualização.

\subsubsection{QUANTO AOS MEIOS}

O estudo bibliográfico é uma análise e interpretação de livros, relatórios, teses, etc. Para esse tipo de pesquisa é necessário planejamento na coleta de dados. Os materiais selecionados devem passar por uma leitura detalhada, sistemática e organizada (ZAMBELLO et al., 2018).

RC: 100720

Disponível em: https://www.nucleodoconhecimento.com.br/contabilidade/gestaopara-microempresas 
Assim, para o desenvolvimento deste artigo foi utilizado o método bibliográfico que teve como base livros, artigos e ideias de autores já publicados.

\section{CONSIDERAÇÕES FINAIS}

Com o objetivo de mostrar que o controle de fluxo de caixa é essencial para manter um negócio saudável financeiramente, este trabalho apresentou algumas perspectivas significativas para o planejamento financeiro através do uso do controle de fluxo de caixa em microempresas.

Respondendo aos objetivos específicos, verificou-se que o controle do fluxo de caixa é capaz de promover respostas precisas e demonstrar a capacidade de liquidez da empresa, mostrando-se para os gestores como uma ferramenta eficiente na organização empresarial.

Sabendo que o fluxo de caixa é uma ferramenta funcional que auxilia no gerenciamento dos recursos financeiros, esta deve ser usada como mecanismo auxiliar no gerenciamento e nas tomadas decisórias administrativas. No que se refere à questão problema do artigo: de que forma o controle de fluxo de caixa poderá atender as necessidades para o planejamento financeiro na gestão das microempresas? Em resposta à pesquisa, foi possível observar que a utilização do fluxo de caixa nas empresas pode oferecer melhorias e transparência nos resultados financeiros e na real necessidade de planejamento e controle financeiro, contribuindo assim para o prolongamento de suas atividades comerciais e no crescimento dessas empresas.

Assim, este artigo buscou contribuir para estrutura gerencial de microempresas, trazendo como ferramenta o controle de fluxo de caixa relacionado ao controle financeiro da empresa.

RC: 100720

Disponível em: https://www. nucleodoconhecimento.com.br/contabilidade/gestaopara-microempresas 


\section{REFERÊNCIAS}

ATKINSON, A. A. et al. Contabilidade gerencial. Tradução de André Olímpio Mosselman du Chenoy Castro, revisão técnica de Rubens Famá. 2. ed. São Paulo: Atlas, 2008.

BLOG. Bom Controle, 2019. Disponível: https://blog.bomcontrole.com.br/projecaode-vendas/. Acesso: 30/09/21.

BRAGA, R. Fundamentos e técnicas de administração financeira. São Paulo: Atlas, 2008.

BRASIL. Lei Complementar no 123 de 14 de dezembro de 2006 . Brasília, 2006. Disponível em: http://www.planalto.gov.br/ccivil_03/leis/lcp/lcp123.htm

CFC. Manual de Contabilidade do Sistema CFC/CRCs. Brasília: CFC, 2009.

CPC. Pronunciamento técnico CPC 03 (R2): demonstração dos fluxos de caixa. 2010.

ENCINAS, J. E.; SANTANA, O. A. O Trabalho Científico na Metodologia Científica. 1. ed. Brasília DF: Universidade de Brasília, 2019.

FERREIRA, C. da F. et al. Gestão de capital de giro: contribuição para micro e pequenas empresas no Brasil. Rio de Janeiro, 2011. Disponível em: https://www.scielo.br/j/rap/a/63XdKH7Q58W7xbVMsnVgLcB/?format=pdf\&lang=pt. Acesso em: 06/09/2021.

FONSECA, R. C. V. da. Metodologia do Trabalho Científico. Edição revista, Curitiba PR: IESDE Brasil S.A, 2012.

GROPPELLI, A. E. Administração Financeira. 3. ed. Atlas, 2009. 
IUDÍCIBUS, S. de. et al. Manual de Contabilidade das Sociedades por Ações: aplicada às demais sociedades. 7. ed. São Paulo: editora Atlas S.A., 2009.

MACHADO, L. de A. A Importância das demonstrações de Fluxo de Caixa como ferramentas de decisão. Goiânia, 2020. Disponível em: https://repositorio.pucgoias.edu.br/jspui/bitstream/123456789/1349/1/TCC\%20LUCA S.pdf. Acesso em: 29/09/21.

MARCONDES, R. C. et al. Metodologia para trabalhos práticos e aplicados, Administração e Contabilidade. São Paulo: editora Mackenzie, 2017.

MENDONÇA, A. C. A Gestão Financeira no Setor de Contas a Pagar. Rio de Janeiro, $2010 . \quad$ Disponível em: http://www.avm.edu.br/docpdf/monografias_publicadas/K215606.pdf. Acesso em: 02/08/2020.

MORAES, J. P.; GOMES, A. M. O Impacto da Inadimplência nas Organizações. Santa Fé do Sul, 2015.

MORAIS, S. Administração financeira: princípios, fundamentos e práticas. Rio de Janeiro: Elsevier, 2010.

PADOVEZE, C. L. Contabilidade Geral. Um enfoque em sistemas de informação contábil. 7. ed. São Paulo: editora Atlas, 2010.

RIBEIRO, O. M. Contabilidade Geral Fácil. 29. ed. São Paulo: editora Saraiva, 2013.

SÁ, C. A. Fluxo de caixa: a visão da tesouraria e da controladoria. 2. ed. São Paulo: Atlas, 2008.

SALAZAR, J. L. A.; BENEDICTO, G. C. de. Contabilidade Financeira. 1. ed. São Paulo: editora Cengage Learning, 2010. 
SEVERINO, A. J. Metodologia do Trabalho Científico. 1. ed. São Paulo: editora Cortez, 2013.

SILVA, J. P. da. Análise Financeira das empresas. 9. ed. São Paulo: Atlas, 2008.

SOUSA, A. Gerência Financeira para micro e pequenas empresas: um manual simplificado. Rio de Janeiro: Elsevier, SEBRAE, 2007.

VELLARDO, C. C. Fluxo de Caixa. Rio de Janeiro: Universidade Candido Mendes, $2010 . \quad$ Disponível em: https://www.avm.edu.br/docpdf/monografias_publicadas/k202106.pdf. Acesso em: 06/09/21.

VIEIRA, V. F. Estratégias para reduzir a inadimplência nas empresas. Rio de Janeiro, 2010, Disponível em: http://www.avm.edu.br/docpdf/monografias_publicadas/k212644.pdf. Acesso em: 09/09/2021

ZAMBELLO, A. V. et al. Metodologia da pesquisa e do trabalho científico. 1. ed. Penápolis: editora FUNEP, 2018.

Enviado: Outubro, 2021.

Aprovado: Novembro, 2021.

RC: 100720

Disponível em: https://www.nucleodoconhecimento.com.br/contabilidade/gestaopara-microempresas 